\title{
Comparison of gene expression patterns between porcine cumulus-oocyte complexes and naked oocytes
}

\author{
G.Y. Zhu ${ }^{1,2}$, S.T. Feng ${ }^{1 \#}$, J.T. Li ${ }^{1}$, Y.L. Mu ${ }^{1}$, D.K. Pan ${ }^{1}$ and B.R. Guo ${ }^{2}$ \\ ${ }^{1}$ Department of Gene and Cell Engineering, Institute of Animal Science, Chinese Academy of Agricultural Sciences, \\ Beijing 100094, P.R. China \\ ${ }^{2}$ College of Life Science, Qufu Normal University, Qufu, Shangdong, 273165, P.R. China
}

\begin{abstract}
Several layers of cumulus cells surround the oocyte in the antral ovarian follicle throughout the follicular development until ovulation. The cumulus cells play an important supportive and regulative role in oocyte development and maturation via intercellular communications between oocytes and cumulus cells. Using the differential display reverse transcriptase polymerase chain reaction (DD-RT-PCR) and semiquantitative RT-PCR methods, we compared the mRNA expression patterns in porcine oocytes from two sources: cumulus-oocyte complexes (COCs) and naked oocytes (NOs). After a small scale screen, 14 differentially expressed mRNAs were cloned, sequenced, and their expression patterns were verified by semi-quantitative RT-PCR. It was confirmed that four mRNAs including three genes (PELP1, Myo5b and $C A S T$ ) and a new EST (Expressed Sequence Tag) are expressed preferentially in the oocytes of COCs rather than in NOs. Previous studies of the three genes suggested that they are mainly involved in oestrogen receptor regulation, membrane trafficking, organelle transport, cellular signalling and some other cellular processes. These results suggest that the aberrant of gene expression patterns detected in the oocytes of NOs compared with COCs explains their reduced quality in terms of development and maturation. In conclusion, these differentially expressed mRNAs may be involved in cellular interactions between oocytes and cumulus cells and thus could be considered as essential genes for the competence of oocytes.
\end{abstract}

Keywords: Differential gene expression, DD-RT-PCR, porcine oocytes, cumulus

${ }^{\#}$ Corresponding author. E-mail: guiyuzhu@hotmail.com, fst508@sina.com

\section{Introduction}

Quite a number of studies that focus on in vitro maturation (IVM) and in vitro fertilization (IVF) of porcine oocytes have been published recently. The quality of oocytes is always considered as the most important factor for determining the efficiency of maturation, fertilization and the embryonic development to the blastocyst stage. Although most porcine oocytes can mature and subsequently be fertilized in vitro, only a few complete the pre-implantation development and implant successfully (Niwa \& Funahashi, 1999; Krisher, 2004).

The oocyte maturation is a mixture of complex mechanisms, which include the intercellular communications between oocytes and surrounding somatic cells within the follicle. The cumulus oophorus is defined as a group of closely associated granulosa cells, called cumulus cells, which surround the oocyte in the follicle. Numerous studies have been reported on the function of the cumulus cells during oocyte maturation, ovulation, fertilization and even embryonic development (Tanghe et al., 2002). The cumulus cells supply the oocytes with nutrients, regulatory molecules and connect them to the external world by means of gap junctions. Cumulus cells mainly exert their essential effects during oocyte maturation by keeping the oocyte under meiotic arrest; participating in the induction of meiotic resumption and supporting cytoplasmic maturation. During ovulation, cumulus cells surrounding the oocyte create a specific microenvironment to facilitate the fertilization in vivo and in vitro (Hillensjo et al., 1982; Eppig, 1991; Im et al., 1995; Sato, 1998; Tanghe et al., 2002; Van Soom et al., 2002; Yokoo \& Sato, 2004). It is likely that the role of cumulus cells during fertilization differs between species and still needs to be clarified. In human, cumulus cells removal prior to insemination increases the fertilization potential of oocytes with a poor fertility, whereas the removal of cumulus cells before in vitro fertilization decreases sperm penetration in cattle (Zhang et al., 1995) and pigs (Wongsrikeao et al., 2005). 
On the level of transcriptional regulation, successful oocyte maturation is dependent on time and location-specific expressions of appropriate genes. During follicle growth the oocyte accumulates mRNAs and proteins (maternal genome) that will enable the oocyte to be fertilized and be developed to 2-cells or 4 to 8-cells (cleavage stage) until activation of the embryonic genome's transcription (Assou et al., 2006). It is reasonable to hypothesize that the genes that are differentially expressed between oocytes with or without cumulus may be the key in oocyte-cumulus communication and should be considered as vitally important genes for oocyte development.

In this study we have applied the DD-RT-PCR method to isolate differentially expressed genes between the oocytes from cumulus-oocyte complexes (COCs) and naked oocytes (NOs). Analysis of these two groups of oocytes using the differential display technique could elucidate the mechanisms of oocyte maturation and screen out the genes involved in the intercellular communication between the oocyte and cumulus cells. The benefit of this method lies in the small quantities of total RNA required for analysis. Further study of these genes could also help to explain the observed differences in maturation between the COCs and NOs, and provide valuable molecular evidence of abnormal gene expression in naked oocytes with lower competence.

\section{Materials and Methods}

Porcine ovaries from prepubertal Landrace gilts were obtained at a local slaughterhouse (Pengcheng Food Company, Beijing, China), stored in warm $\left(30-35^{\circ} \mathrm{C}\right)$ normal saline supplemented with penicillin $(200 \mathrm{IU} / \mathrm{mL})$ and streptomycin $(50 \mathrm{~g} / \mathrm{mL})$ (Sigma, USA), and transported to the laboratory within $1 \mathrm{~h}$ of collection. After washing, follicles with a diameter of $2-8 \mathrm{~mm}$ of randomly selected ovaries were aspirated. Within $2 \mathrm{~h}$ follicle aspiration was performed under sterile conditions with an 18-gauge needle and a disposable syringe. The follicle content was sedimentated in $15 \mathrm{~mL}$ conical tubes in $37{ }^{\circ} \mathrm{C}$. After the sedimentation, the follicle content was washed twice with PBS (Dingguo Bio, Beijing, China). Naked oocytes with no cumulus, and oocytes with intact and more than five compact cumulus layers were selected and pooled under a dissecting microscope. The COCs were then completely denuded of their surrounding cumulus cells with $0.1 \%$ hyaluronidase (Sigma, USA) and pipetting, so that only oocytes within the COCs were isolated. A Tyrode's solution $(\mathrm{pH}=2.0-2.5)$ was added to dissolve the zona pellucidue of both types of oocytes. After a second wash with PBS, the same amount (about 100 cells) of normal oocytes or naked oocytes was added into single tubes containing a lysis buffer consisting of $20 \mathrm{mM} \mathrm{DTT}, 0.5 \% \mathrm{NP}-40$ and $1 \mathrm{U} / \mathrm{L}$ Rnasin (Sigma, USA ). Collection of oocytes was replicated 10 times. Samples were then snap frozen in liquid nitrogen and stored at $-80{ }^{\circ} \mathrm{C}$. Before RNA extraction, samples were incubated at $65^{\circ} \mathrm{C}$ for 5 min to facilitate the lysis of the oocytes and the release of RNA. The RNeasy Micro Kit (Qiagen, USA) was employed to isolate the RNA according to the manufacturer's instructions. RNA was quantified with an ultraviolet spectrophotometer, adjusted to the same concentration and the integrity was checked by electrophoresis.

The DDRT-PCR was performed using the One Step RT-PCR Kit (Qiagen, USA) employing an optimized protocol. Briefly, the $25 \mathrm{~L}$ total reaction volume contained $2.5 \mathrm{mM}$ of $\mathrm{MgCl}_{2}, 1.0 \mathrm{M}$ of anchoredrandom primers (Table 1), $400 \mathrm{M}$ of each dNTP, $5 \times$ RT-PCR buffer, 2 units of RNase inhibitor and $1.0 \mathrm{~L}$ Enzyme Mix. Each $1 \mathrm{~g}$ RNA from normal oocytes or naked oocytes was added to individual PCR tubes as template. The following conditions were used for reverse transcription and amplification: $30 \mathrm{~min}$ at $50{ }^{\circ} \mathrm{C}$, 15 min at $95^{\circ} \mathrm{C}, 40$ cycles of $1 \mathrm{~min}$ at $94{ }^{\circ} \mathrm{C}, 2 \mathrm{~min}$ at $42{ }^{\circ} \mathrm{C}, 2 \mathrm{~min}$ at $72{ }^{\circ} \mathrm{C}$ and a final extension step of 10 min at $72{ }^{\circ} \mathrm{C}$. The housekeeping gene, $\beta$-actin, was employed as an internal control to test the RT-PCR efficiency and normalization. Reactions consisting of RT-PCR reaction mixture without added sample template were always included to ensure absence of contamination.

The amplified cDNAs were electrophoresed on 5\% polyacrylamide gel. After silver staining, cDNA bands showing large intensity differences between COCs and NOs were excised and purified, employing the PAGE Purification Kit (Tiangen Bio, Beijing, China). The purified cDNA fragments were subjected to re-amplification, which performed in a total volume of $10 \mu \mathrm{L}$ in $1 \times$ PCR buffer (TaKaRa, Dalian, China), containing the purified cDNA, $0.3 \mu \mathrm{M}$ of each anchored-random primer combination (Table 1 ), $75 \mu \mathrm{M}$ each dNTP, $1.5 \mathrm{mM} \mathrm{MgCl}_{2}$, and 1.0U Taq DNA polymerase (TaKaRa, Dalian, China). The PCR profile consisted of $3 \mathrm{~min}$ at $94{ }^{\circ} \mathrm{C}, 35$ cycles of $20 \mathrm{~s}$ at $94{ }^{\circ} \mathrm{C}, 20 \mathrm{~s}$ at $42{ }^{\circ} \mathrm{C}$, and $20 \mathrm{~s}$ at $72{ }^{\circ} \mathrm{C}$, and a final 5 -min extension at $72{ }^{\circ} \mathrm{C}$. The PCR product was purified and subsequently cloned into the pMD-18T vector (TaKaRa) prior to 
sequencing. The sequences were used to search the NCBI databases for homology to known genes or ESTs using the BLAST sequence analysis program.

Table 1 Primers and PCR conditions

\begin{tabular}{|c|c|c|c|}
\hline Clone & PCR primers (5'-3') & Size (bp) & $\begin{array}{l}\text { Annealing temperature } \\
\left({ }^{\circ} \mathrm{C}\right)\end{array}$ \\
\hline A01 & $\begin{array}{l}\text { ACTTTATTGGAAACGAGGCG } \\
\text { GCAGAAGAAATGGAGACGGA }\end{array}$ & 180 & 58 \\
\hline A03 & $\begin{array}{l}\text { CCCATTTAATCCATCTTCTC } \\
\text { TATAGCTCACTCTGCACAAA }\end{array}$ & 221 & 58 \\
\hline $\mathrm{C} 01$ & $\begin{array}{l}\text { GTTTCCTTTTAGTGACTGACC } \\
\text { TGGGAACTCAATCCAAATCA }\end{array}$ & 208 & 59 \\
\hline $\mathrm{C} 02$ & $\begin{array}{l}\text { ACGGCTGATTTACTTGAGAA } \\
\text { CGTATCAGTCTTTGCTCCTC }\end{array}$ & 81 & 60 \\
\hline $\mathrm{C} 04$ & $\begin{array}{l}\text { CAAGGGGTTTATGAGGGGTCA } \\
\text { GCTTGCCTTCAACTATCTATG }\end{array}$ & 131 & 59 \\
\hline C05 & $\begin{array}{l}\text { AAGGATGTAGCCAAGGAGGG } \\
\text { TGCTTTGGGTTTGAGTGGTA }\end{array}$ & 119 & 60 \\
\hline C06 & $\begin{array}{l}\text { AGGATTCCACAAAGGCAAAG } \\
\text { ATACCACTAGAAGCCACCCA }\end{array}$ & 177 & 58 \\
\hline $\begin{array}{l}\text { anchored-random } \\
\text { primers } 1\end{array}$ & $\begin{array}{l}\text { AAGCTTTTTTTTTTTTTTTC } \\
\text { AAGCTTGATTGCC }\end{array}$ & & 42 \\
\hline $\begin{array}{l}\text { anchored-random } \\
\text { primers } 2\end{array}$ & $\begin{array}{l}\text { AAGCTTTTTTTTTTTTTTTG } \\
\text { AAGCTTTGGTCAG }\end{array}$ & & 42 \\
\hline $\begin{array}{l}\text { anchored-random } \\
\text { primers } 3\end{array}$ & $\begin{array}{l}\text { AAGCTTTTTTTTTTTTTTTA } \\
\text { AAGCTTAACGAGG }\end{array}$ & & 42 \\
\hline$\beta$-actin & $\begin{array}{l}\text { GGACTTCGAGCAGGAGATGG } \\
\text { GCACCGTGTTGGCGTAGAGG }\end{array}$ & 233 & 60 \\
\hline
\end{tabular}

Almost half the sequenced fragments was selected to do a verification analysis. Differential expressions of these mRNAs were confirmed by semi-quantitative RT-PCR, using the same template with the protocol suggested by the manufacturer employing the individual pairs of fragment-specific primers with reduced amplification cycles (Table 1). The products were analyzed on $2 \%$ agarose gels containing ethidium bromide. The positive control $\beta$-actin and the no template negative control were included and all the reactions were performed at least twice.

\section{Results}

The differential bands were obtained by using three pairs of anchored-random primers. For each combination, three replicates of analyses were done, and the band patterns derived from the parallel reactions were highly similar. Finally, 16 bands that exhibited a consistent differential expression pattern in the triplicate experiments were excised from the gel and analyzed further. Fourteen of them were re-amplified successfully and then subjected to sequencing.

The length of the 14 cDNA fragments excised from the gel, ranged from 105 to 524bp. All the sequences had the anchored oligo (dT) on one extremity and the 13 mer at the other end. Moreover, 11 out of the 14 contained the polyadenylation signal (AATAAA), indicating that they were indeed mRNA 3 'end region sequences. A sequence similarity search was performed in the databases available in GenBank. Three cDNAs (A01, A03, C06) showed sequence similarities to genes in the GenBank. They were PELP1 (proline-, glutamic acid- and leucine-rich protein), Myo5b (Myosin5b) and CAST (calpastatin). The clone A01, A03 and C06 showed 87\%, 83\% and 100\% homologous with human PELP1 gene, human Myo5b gene and pig CAST gene, respectively. Five cDNAs displayed sequence similarities to expressed sequence tags, but their functions were unknown. The detailed information of the cDNAs is shown in Table 2. 
Table 2 Characterization of clones isolated by differential display

\begin{tabular}{llllll}
\hline Clone & $\begin{array}{l}\text { GenBank } \\
\text { Accession } \\
\text { number }\end{array}$ & $\begin{array}{l}\text { Size } \\
(\mathrm{bp})\end{array}$ & \multicolumn{2}{l}{$\begin{array}{l}\text { Specificity } \\
\text { COC }\end{array}$} & NO \\
A01 & EC093161 & 136 & + & - & $\begin{array}{l}\text { Homo sapiens proline, glutamic acid and leucine } \\
\text { rich protein 1 (PELP1) mRNA }\end{array}$ \\
A02 & EC093162 & 114 & + & - & Unknown \\
A03 & EC093163 & 223 & + & - & Homo sapiens myosin 5B (MYO5B) mRNA. \\
A04 & EC093164 & 220 & + & - & Unknown \\
B01 & EC093165 & 140 & - & + & Unknown \\
B02 & EC093166 & 105 & + & - & Unknown \\
B03 & EC093167 & 136 & + & - & Unknown \\
C01 & EC093168 & 179 & + & - & Porcine EST CJ032503 \\
C02 & EC093169 & 265 & + & - & Porcine EST DN123315 \\
C03 & EC093170 & 299 & + & - & Unknown \\
C04 & EC093171 & 351 & - & + & Porcine EST DN117003 \\
C05 & EC093172 & 466 & + & - & Porcine EST CJ028576 \\
C06 & EC093173 & 256 & + & - & Sus scrofa heart calpastatin mRNA \\
C07 & EC093174 & 524 & + & - & Porcine EST DY404546 \\
\hline
\end{tabular}

a Only detected in the oocytes of COCs or NOs
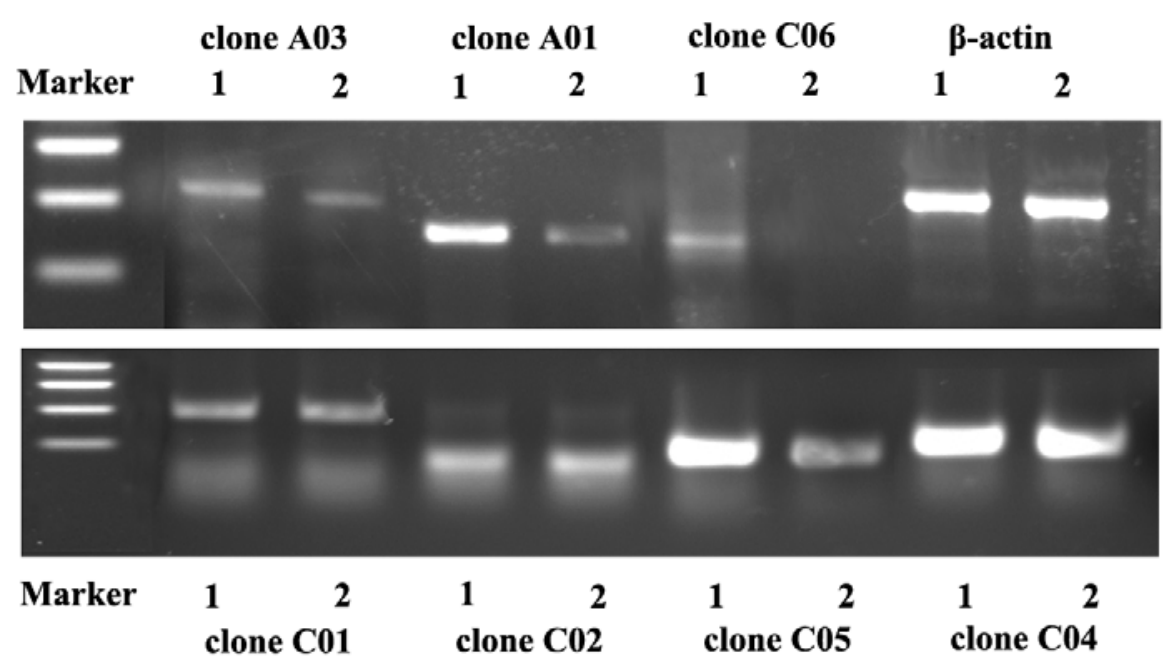

Figure 1 Semi-quantitative RT-PCR analysis of differentially displayed cDNAs. The sample RNAs from the two kinds of oocytes were normalized to achieve semi-quantification. The housekeeping gene, $\beta$-actin, was used as an internal standard to control RNA quantity between two kinds of cells. The number of cycles in all reactions was set at 25, except for the clone C06 (35 cycles). The clone numbers and the origin of templates (1: RNA from oocytes in COCs; 2: RNA from NOs) are indicated in the figure. 
Differential expression of the transcripts was tested by semi-quantitative RT-PCR. Seven clones including A01, A03, C06 (known genes), C01, C02, C04, and C05 (unknown) were tested twice to confirm whether the selected fragments were authentic positive clones. A significant $\beta$-actin signal of the same intensity was obtained with the two kinds of template RNAs after 25 cycles of amplification. As Figure 1 shows, only four fragments (A01, A03, C06, and C05) were found to be consonant with the expression pattern in PAGE gels and therefore validated as positive clones. The other clones did not show any visible differences in signal intensity between the two samples, and thus, were designated as false positive clones. These results indicate that half of the cDNAs isolated from the differential display was truly differential expressed mRNAs. Three clones (A01, A03, and C05) represented PELP1, Myo5b genes and a new EST, expressed more abundantly in the oocytes of COCs than NOs; whereas, clone C06, the CAST gene, showed no expression in NOs, even after 35 cycles of amplification. Clone (C04) was one of the two bands that were detected preferentially in the NOs rather than COCs in differential display. However, the RT-PCR analysis showed nearly identical expression between the two samples, indicating that it is an artifact caused by the differential display procedure.

\section{Discussion}

This study demonstrated that the aberrant of gene expression patterns detected in the oocytes of NOs compared with COCs explains their reduced qualities in terms of development and maturation. These differentially expressed mRNAs may be also involved in the cellular interactions between oocytes and cumulus cells and thus could be considered as essential genes for the competence of oocytes.

The DD-RT-PCR comparisons were performed to find genes in porcine oocytes associated with the presence or absence of cumulus cells. The different pools of oocytes were specifically sorted based on the status of cumulus of the enclosed oocytes. Then the information of the interaction between oocytes and cumulus cells could be deduced through a comparison of gene expression patterns between these two kinds of oocytes. The DD-RT-PCR method with one-step RT-PCR procedure was used. After 25 cycles of amplification and agarose electrophoresis, the housekeeping $\beta$-actin gene expression was observed to be identical between the two pools of oocytes. This suggested that the mRNA template was well controlled between samples. To confirm the differential regulation of mRNAs obtained by differential display, some kind of verification experiments was needed. Considering that the starting quantities of RNAs are too rare to be detected by Northern analysis, we employed semi-quantitative RT-PCR instead. After the RT-PCR confirmation, almost half of the cDNA bands showed consonant expression patterns with the differential display. Sequences of clones have been compared with sequences available in GenBank, and only three clones (A01, A03, and C06) were homologous to previously described genes and five others (C01, C02, C04, $\mathrm{C} 05$, and C07) with porcine ESTs. The other clones have no sequence similarity with any identified sequence in the databases. This may be attributed to their short length or the great variation of the 3' untranslated region. More sequence information is needed before it can be concluded that these are actually new genes. Finally, we identified three genes and a new EST that were preferentially expressed in oocytes of COCs rather than of NOs.

One sequence (clone A01) was found to be similar to the human gene encoding proline-, glutamic acid- and leucine-rich protein (PELP1), a recently identified co-activator of oestrogen receptor (ER), which plays an important role in oestrogen-mediated genomic and nongenomic functions via the Src/mitogeneactivated protein kinase pathways (Vadlamudi et al., 2001; Wong et al., 2002; Balasenthil \& Vadlamudi, 2003). PELP1 interacts with ER $\alpha$ and ER $\beta$, the PELP1 expression is developmentally regulated in mammary glands and its overexpression could sensitize cells to oestrogen-mediated cell cycle progression (Balasenthil \& Vadlamudi, 2003). In this experiment porcine PELP1 gene transcription was much more abundant in the oocytes of COCs than in that of NOs, suggesting that the enhanced expression of PELPI and its participation in the modulation of the cell response of oestrogen were possibly a consequence of oocyte and cumulus interaction.

Another sequence, clone A03, matched with the human Myosin5b gene in 3'UTR. Myosins are oligomeric proteins consisting of one or two heavy chains and varying numbers of light chains. The class $\mathrm{V}$ myosins (Myo5a, Myo5b and Myo5c) have been widely suggested to provide a molecular basis for actindependent organelle transport (DePina \& Langford, 1999; Tuxworth \& Titus, 2000) and membrane trafficking (Reck-Peterson et al., 2000). Myo5b has recently been implicated in the function of a rab11a- 
associated recycling endosome in HeLa cells and in a rab11a-associated recycling compartment required for transcytosis in MDCK cells (Lapierre et al., 2001). The transport of a specific glutamate receptor subunit in neurons also was mediated by myo5b (Lise et al., 2006). In this study, Myo5b was preferentially expressed in the oocytes of COCs, indicating that it was involved in the communication between oocytes and cumulus cells, possibly through the regulation of intracellular or intercellular transportation.

The sequence of clone C06 was identical to the 3'UTR of the porcine CAST gene. The calpaincalpastatin system has been implicated in various cellular signalling pathways mediated by calcium, including membrane-associated events such as cytoskeleton reorganization, enzyme mobilization, receptor activation and other fundamental cellular processes such as cell cycle regulation, cell differentiation and apoptosis (Croall et al., 1991; Carafoli \& Molinari, 1998). Calpains cleave their target proteins in a restricted manner, modifying their properties (Suzuki et al., 1998). Calpastatin, an endogenous inhibitor of calpains, regulates the protease activity of calpains by associating and dissociating with the enzyme (Barnoy et al., 1998). In porcine, CAST was a candidate gene for growth and meat quality traits (Choi et al., 2006). In humans, $C A S T$ was found uniformly distributed throughout the ooplasm, with a marked accumulation at the oocyte membrane by the immunofluorescence method (Ben-Aharon et al., 2005). However, the expression of $C A S T$ was undetectable in the naked oocytes in this study. The absence of CAST in the naked oocytes together with the membrane localization in the normal COCs implies a possible involvement of the calpaincalpastatin pathway with the communication between oocytes and cumulus cells.

\section{Conclusion}

Three genes and some unknown ESTs were identified to be differentially expressed between the COCs and NOs. Larger scaled screening and more detailed characterization of the differentially expressed genes will be needed to further elucidate the mechanisms of oocyte-cumulus communication. As expected, the oocytes with COCs were more competent than the naked ones. Most of the naked oocytes failed to undergo cleavage. Moreover, these genes found in the normal oocytes with more competence could be employed as makers for the selection of more promising oocytes for in vitro manipulation.

\section{Acknowledgements}

This research was supported by the "863 Project" from the Science and Technology Ministry of China (2003AA205100) and the National 10th Five-year Scientific Project of China for Tackling the Key Problems (2004BA717B).

\section{References}

Assou, S., Anahory, T., Pantesco, V., Carrour, T.L., Pellestor, F., Klein, B., Reyftmann, L., Dechaud, H., Vos, J.D. \& Hamamah, S., 2006. The human cumulus-oocyte complex gene-expression profile. Hum. Reprod. 21, 1705-1719.

Balasenthil, S. \& Vadlamudi, R.K., 2003. Functional interactions between the estrogen receptor coactivator PELP1/MNAR and retinoblastoma protein. J. Biol. Chem. 278, 22119-22127.

Barnoy, S., Glaser, T. \& Kosower, N.S., 1998. The calpain-calpastatin system and protein degradation in fusing myoblasts. Biochim. Biophys. Acta. 1402, 52-60.

Ben-Aharon, I., Ben-Yosef, D., Amit, A. \& Shalgi, R., 2005. Expression and immunolocalization of the calpain-calpastatin system in the human oocyte. Fertil. Steril. 83, 1807-1813.

Carafoli, E. \& Molinari, M., 1998. Calpain: a protease in search of a function? Biochem. Biophys. Res. Commun. 247, 193-203.

Choi, B.H., Lee, J.S., Jang, G.W., Lee, H.Y., Lee, J.W., Lee, K.T., Chung, H.Y., Park, H.S., Oh, S.J., Sun, S.S., Myung, K.H., Cheong, I.C. \& Kim, T.H., 2006. Mapping of the porcine calpastatin gene and association study of its variance with economic traits in pigs. Asian-Aust. J. Anim. Sci. 19, 1085-1089.

Croall, D.E. \& DeMartino, G.N., 1991. Calcium-activated neutral protease (calpain) system: structure, function, and regulation. Physiol. Rev. 71, 813-847.

DePina, A.S. \& Langford, G.M., 1999. Vesicle transport: the role of actin filaments and myosin motors. Microsc. Res. Technol. 47, 93-106.

Eppig, J.J., 1991. Intercommunication between mammalian oocytes and companion somatic cells. Bioessays $13,569-574$. 
Hillensjo, T., Magnusson, C., Ekholm, C., Billig, H. \& Hedin, L., 1982. Role of cumulus cells in oocyte maturation. Adv. Exp. Med. Biol. 147, 175-188.

Im, K.S., Kim, H.J., Chung, K.M., Kim, H.S., Park, K.W. \& Niwa, K., 1995. Effect of granulosa and cumulus cells on in vitro development of the bovine follicular oocytes. Asian-Aust. J. Anim. Sci. 8, 317-320.

Krisher, R.L., 2004. The effect of oocyte quality on development. J. Anim. Sci. 82, E-Suppl. E14-23.

Lapierre, L.A., Kumar, R., Hales, C.M., Navarre, J., Bhartur, S.G., Burnette, J.O., Provance Jr., D.W., Mercer, J.A., Bahler, M. \& Goldenring, J.R., 2001. Myosin vb is associated with plasma membrane recycling systems. Mol. Biol. Cell 12, 1843-1857.

Lise, M.F., Wong, T.P., Trinh, A., Hines, R.M., Liu, L., Kang, R., Hines, D.J., Lu, J., Goldenring, J.R., Wang, Y.T. \& El-Husseini, A., 2006. Involvement of myosin Vb in glutamate receptor trafficking. J. Biol. Chem. 281, 3669-3678.

Niwa, K. \& Funahashi, H., 1999. Recent development in embryo technology in pigs (A review). Asian-Aust. J. Anim. Sci. 12, 966-975.

Reck-Peterson, S.L., Provance Jr, D.W., Mooseker, M.S. \& Mercer, J.A., 2000. Class V myosins. Biochim. Biophys. Acta 1496, 36-51.

Sato, E., 1998. Morphological dynamics of cumulus-oocyte complex during oocyte maturation. Ital. J. Anat. Embryol. 103, 103-118.

Suzuki, K. \& Sorimachi, H., 1998. A novel aspect of calpain activation. FEBS Lett. 433, 1-4.

Tanghe, S., Van Soom, A., Nauwynck, H., Coryn, M. \& de Kruif, A., 2002. Minireview: Functions of the cumulus oophorus during oocyte maturation, ovulation, and fertilization. Mol. Reprod. Dev. 61, 414-424.

Tuxworth, R.I. \& Titus, M.A., 2000. Unconventional myosins: anchors in the membrane traffic relay. Traffic $1,11-18$.

Vadlamudi, R.K., Wang, R.A., Mazumdar, A., Kim, Y., Shin, J., Sahin, A. \& Kumar, R., 2001. Molecular cloning and characterization of PELP1, a novel human coregulator of estrogen receptor alpha. J. Biol. Chem. 276, 38272-38279.

Van Soom, A., Tanghe, S., De Pauw, I., Maes, D. \& de Kruif, A., 2002. Function of the cumulus oophorus before and during mammalian fertilization. Reprod. Domest. Anim. 37, 144-151.

Wong, C.W., McNally, C., Nickbarg, E., Komm, B.S. \& Cheskis, B.J., 2002. Estrogen receptor-interacting protein that modulates its nongenomic activity-crosstalk with Src/Erk phosphorylation cascade. Proc. Natl. Acad. Sci. U.S.A. 99, 14783-14788.

Wongsrikeao, P., Kaneshige, Y., Ooki, R., Taniguchi, M., Agung, B., Nii, M. \& Otoi, T., 2005. Effect of the removal of cumulus cells on the nuclear maturation, fertilization and development of porcine oocytes. Reprod. Domest. Anim. 40, 166-170.

Yokoo, M. \& Sato, E., 2004. Cumulus-oocyte complex interactions during oocyte maturation. Int. Rev. Cytol. 235, 251-291.

Zhang, L., Jiang, S., Wozniak, P.J., Yang, X. \& Godke, R.A., 1995. Cumulus cell function during bovine oocyte maturation, fertilization, and embryo development in vitro. Mol. Reprod. Dev. 40, 338-344. 